\title{
Moderne und/versus Tradition - wie verträgt sich das?
}

\author{
Jean Martin \\ Dr. med., Mitglied der Redaktion
}

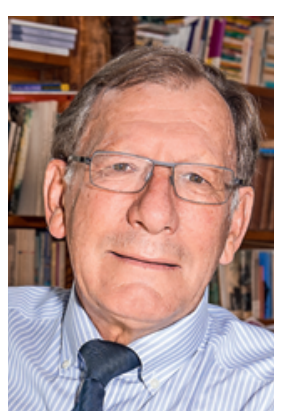

Ich wünsche allen frohe Festtage und ein gutes neues Jahr!
1. Sadin E. La silicolonisation du monde. Paris: Ed. L'Echappée, 2016. Auch: Radiointerview $R T S$ "La Première», 7.35-8.00 Uhr, 1. November 2016 . 2.Sloterdijk P. Après nous le déluge. Paris: Payot, 2016. Auch: Interview dazu in $L e$ Figaro (Paris), 23. Oktober 2016; die Zitate sind daraus entnommen.
Erneut nähert sich das Jahresende - einerseits Zeit, um Bilanz zu ziehen, gleichzeitig aber auch, um den Blick in die Zukunft zu richten. Ich bin beeindruckt, wie kritisch sich bedeutende Philosophen zur aktuellen Entwicklung äussern. Der Franzose Eric Sadin (1973) erhebt seine Stimme gegen die "Sili-Kolonisierung» unserer Welt. Er macht sich Sorgen über unser Abdriften in eine Gesellschaft, die ihr Augenmerk vor allem auf die Messung legt [1]. NB: Hierbei geht es nicht um Messung im Sinne von Abwägung, sondern um eine zwanghafte Quantifizierung im Alltag. Der Trend hin zum quantified self ist ein gutes Beispiel. Sadin will eine humanistische Erneuerung, sieht jedoch rot, wenn von digitalen Geisteswissenschaften die Rede ist! In französischer Tradition ruft er nach einer qualitativen Rückbesinnung auf traditionelle Werte - diese Rückbesinnung sollte durch entsprechendes Engagement aus der Zivilgesellschaft gefördert werden. Glücklicherweise ist heute zwar eine gewisse Entwicklung hin zu alternativen Lebens- und Produktionsarten festzustellen, eine anti-digitale Grundströmung lässt sich daraus jedoch kaum ableiten. So dürfte sich beispielsweise wohl kaum Widerstand gegen eine immer genauere Diagnostik regen, die durch die Digitalisierung möglich wird.

Der grosse deutsche Denker Peter Sloterdijk (1947) - er lehrt an der Staatlichen Hochschule für Gestaltung in Karlsruhe - setzt in seinem Werk Après nous le déluge [Die schrecklichen Kinder der Neuzeit] [2] Tradition und Moderne gegeneinander und diskutiert das Ungleichgewicht einer Welt, die die Vergangenheit hinter sich gelassen hat. "Modernisierung geht immer weiter in Richtung Entwurzelung, hin zu einem Verleugnen des Ursprungs, zu einem Leben ohne Deszendenz.» Oder: «Die traditionelle Weltenordnung war bislang geprägt durch zwei wesentliche Merkmale: die Sterblichkeit des Individuums und die Fortdauer von Kulturen. So seine Ontologie. Die Moderne führt - im Darwinischen Sinne - den Gedanken ein, dass selbst 'Zivilisationen verschwinden können'» - ein Gedanke, den Paul Valéry bereits vor einem Jahrhundert vorgedacht hat.

Sloterdijk interessiert sich für die zwischen den Generationen bestehende Bindung: «Eine echte Kontinuität zwischen Eltern und Kindern hat es letztlich nie gege- ben. Aber die alte Welt versuchte - mit beträchtlichem Erfolg - sich den Anschein zu geben, als sei Kontinuität stärker als Diskontinuität. Ab der Renaissance begann ein neuer Zyklus, in dem die Innovatoren das Wort hatten und Wissen in den Vordergrund stellten. Modernisierung öffnet die Generationsgräben.»

Ein Gedanke Sloterdijks steht im Gegensatz zu meiner Überzeugung, dass Verschmelzungen kultureller und biologischer Art belebend und bereichernd sind: «In der modernen Reflektion gilt Bastardierung als chic und man nennt sie stolz 'Verschmelzung von Kulturen'. Modernisten wollen die Grenzen des Normalen ausweiten" (es wird nicht überraschen, dass er nicht viel vom Transhumanismus hält). «Natürlich steht die Moderne für Toleranz, gleichzeitig aber auch für eine Zivilisation, die riskiert, sich ihrer selbst zu entledigen.» Nun ... ich (J. M.) bin weiterhin der Ansicht, dass die Fähigkeit zur Toleranz wichtig ist und wir versuchen müssen, die Tendenzen zur Vermischung und Verschmelzung so gut wie möglich zu steuern (ein Verbieten oder Auslöschen kommt nicht in Frage).

Dazu Sloterdijk: «Die Kontrolle über ein Fahrzeug setzt einen Mechanismus voraus, mit dem wir es stoppen können. Unsere Zivilisation ist nur mit der einen Hälfte des Fahrvorgangs (dem Beschleunigen) vertraut. Es ist eine Zugfahrt ohne Lokführer und ohne Bremsen; man weiss nicht einmal, ob die Gleise gesetzt wurden.» Was sollen wir davon halten, wenn ein Denker dieses Formats betont, dass «der grösste Aberglaube in der Überzeugung besteht, an der Spitze des Fortschritts zu marschieren»! In diesem Kontext ist auch die Diskussion über die künstliche Intelligenz zu nennen, wenn - als Antwort auf zum Ausdruck gebrachte Ängste - immer wieder versichert wird, dass cyber-physische Tools und Vorrichtungen niemals ohne uns Entscheidungen treffen werden und wir solche Prozesse immer frühzeitig stoppen können.

Ich werde die Feiertage jedenfalls im Kreise der Familie verbringen, umgeben von Kindern und Enkelkindern. Und ich werde das Beisammensein intensiv geniessen. Allerdings bleibe ich nachdenklich. Glücklicherweise empfiehlt auch Sloterdijk einen unerschütterlichen Optimismus. Allerdings erklärt er nicht, wie sich ein solcher realisieren lässt! 